\title{
Application of Bioactive Coatings Based on Chitosan for Soybean Seed Protection
}

\author{
Defang Zeng, Xinrong Luo, and Renjie Tu \\ School of Resource \& Environmental Engineering and Key Laboratory of Hubei Province for Mineral Resources Processing and \\ Environment, Wuhan University of Technology, Wuhan 430070, China
}

Correspondence should be addressed to Defang Zeng, turenjie617@163.com

Received 6 December 2011; Revised 7 March 2012; Accepted 18 March 2012

Academic Editor: José A. Lopes da Silva

Copyright ( 92012 Defang Zeng et al. This is an open access article distributed under the Creative Commons Attribution License, which permits unrestricted use, distribution, and reproduction in any medium, provided the original work is properly cited.

Soybean seeds suffer attacks of various pests that result in a decreased yield in northeastern China. Until recently, people use pesticides such as insecticides to achieve the goal of controlling pests. Chitosan extracted from deacetylation of chitin is promising candidates as a seed-coating agent to control agrotis ypsilon, soybean pod borer, and soybean aphid effectively. An experimental study on influences of chitosan with different concentrations on pest controlling and soybean growth was made in the paper. Coating based on chitosan was used as a feeding deterrent and for enhancing the germination and quality of soybean seeds. Results indicated that all chitosan coating had a significant effect on antifeeding against pests; with the increasing concentration, antifeedant rate (AR) were increased obviously, especially when in the concentration of 5\%, santifeedant rate of agrotis ypsilon, soybean pod borer, and soybean aphid reached $82.89 \%, 87.24 \%$, and $80.21 \%$, respectively. Also chitosan coating increased seed germination, plant growth, and soybean yield efficiently, especially when, in the concentration of 5\%, the yield was increased by about $20 \%$ compared with CK. The application of chitosan in soybean seed coated is an appropriate option to control pests replacing high-toxicity pesticides and enhance soybean yield.

\section{Introduction}

Soybean is one of the major economic crops and famous for its rich plant proteins in China. However, during the soybean growth process, soybean suffers attacks of various pests such as agrotis ypsilon, soybean pod borer, and soybean aphid that result in considerable crop losses in northeastern China. Agrotis ypsilon is a cosmopolitan important underground pest with a wide distribution in China, which can attack many kinds of seedlings of crops and trees. Soybean pod borer is a devastating insect pest of many legume crops in tropical and semitropical regions, such as Africa and southeastern Asia. Larvae are pale-colored and feed on the floral parts and pods of legume plants, rendering them unmarketable. Plants are not killed, but a large proportion of the pods may be damaged and unmarketable. Flowers are also eaten and destroyed. Soybean aphid has a tubelike mouthpart that sucks juices and nutrients from the plant. Plants may yellow and become stunted, reducing pod and seed production if aphid populations become extremely high. The honeydew acts as a substrate for sooty mould to develop which turns the leaves black and rubbery.

To prevent considerable economic losses, many studies [1-3] have developed for crop protection, such as seedcoated technology as a pesticide against crop pests and diseases. Results indicated that it can prevent the seeds from pests in the soil and plant and improve the germination potential: germination percentage and crop yield [4]. Therefore, soybean seeds are usually coated by seed-coating agents before being planted in Northeast China [5]. Results are usually positive since the number of pests is reduced, and the quality of the seeds is improved when conventional treatments are used. However, these conventional seed-coating agents are not the best alternative for the environment due to their accumulative toxicity in the soil. In addition, pests may develop resistance against them, which implies the use of increasingly larger amounts to be efficient $[6,7]$. Thus, there is a demand for a safer and more ecofriendly alternative $[8,9]$. 
Chitosan is a carbohydrate biopolymer derived from deacetylation of chitin, which is found in the crustacean's shells, insect's cuticle, and cell wall of fungi. The positive charge of chitosan confers to this polymer numerous and unique physiological and biological properties with great potential in a wide range of industries such as pharmacology, medicine, and agriculture [10-12].

This effect has been shown when seeds were treated by chitosan solutions; these treatments improved the germination of several cultures and contributed to harvests yields. The application of chitosan in agriculture consisted of coating seeds and plants by dipping or spraying. The main objective of this study was to investigate the effect of chitosan as a seed treatment on insect pest control, seed germination, soybean growth, and yield.

\section{Materials and Methods}

Chitosan (Aokang Biotech Co., China), soybean seeds (Wuyin number nine, Hubei Seed Co., China). Agrotis ypsilon, soybean pod borer, and soybean aphid (Fourth instars larvae, Shandong Agricultural University, China), sodium hydroxide, and acetic acid (analytically pure, Hubei University Chemical Plant).

Chitosan was dissolved at $1 \%, 2 \%, 3 \%, 4 \%$, and $5 \%(\mathrm{w} / \mathrm{v})$ into aqueous solutions of acetic acid at $1 \%(\mathrm{w} / \mathrm{v})$. The $\mathrm{pH}$ of solution was adjusted to 6.0 using $1 \% \mathrm{NaOH}$. Soybean seeds $(10 \mathrm{~g})$ were introduced into a seed coater. During the rotation of the coater, $0.2 \mathrm{~mL}$ solution treatment was added to the seeds. After coating, seeds were air-dried for $2 \mathrm{~h}$ at room temperature.

2.1. Laboratory Method for Antifeeding Test. According to the guideline for laboratory bioassay of pesticides, the antifeeding effect of chitosan was studied in no-choice bioassays with the artificial mixed feeding method and leaf discs method. The artificial mixed feeding method was as follows: $100 \mathrm{~g}$ artificial feed was individually dipped in different concentrations of chitosan solutions and then put into each hole with diameter of $1.5 \mathrm{~cm}$ and depth of $1.5 \mathrm{~cm}$, where the fourth instars larvae were fed. The leaf discs method was as follows: fresh cotton leaf discs of $4 \mathrm{~cm}$ diameter were punched using a cork borer and were individually dipped in different concentrations of chitosan solutions. Each fourth instars larva was introduced into per Petri dish. Artificial feeds and leaf discs treated with water (CK) were used as controls, and each treatment was replicated 3 times. The antifeeding effect was determined at $48 \mathrm{~h}$ after breeding in the incubator at temperature of $25 \pm 1^{\circ} \mathrm{C}$ and $75-85 \%$ relative humidity under a day length of $16 \mathrm{~L}: 8 \mathrm{D}$. An electronic balance and a leaf area meter were used to measure the consumption. The test was valid only at less than 5\% mortality of larvae. The nonselective antifeedant rate (AR) was calculated by the following formula:

$$
\mathrm{AR}(\%)=\frac{A-B}{A} \times 100 \%,
$$

where $A$ and $B$ are the consumption of the control group and the treatment group, respectively.
2.2. Laboratory Method for the Germination Abilities Test. According to the rules for seed testing of the International Seed Testing Association [13], 100 seeds taken from each group were arranged on two layers of wet filter paper in each Petri dishes filled with wet sand. Each Petri dish contained 25 seeds, and each treatment was replicated 4 times. All Petri dishes were incubated in the constant temperature and humidity incubator at $28 \pm 1^{\circ} \mathrm{C}$ and air relative humidity of $85 \%$. Germinability (GE), germination percentage (GP), and germination index (GI) of soybean seeds were investigated on the third day and seventh day, respectively. The calculation formulas were as follows:

$$
\begin{aligned}
\mathrm{GE} & =\frac{C}{E} \times 100 \%, \\
\mathrm{GP} & =\frac{D}{E} \times 100 \%, \\
\mathrm{GI}(\%) & =\sum \frac{F}{G} \times 100 \%,
\end{aligned}
$$

where $C$ is the number of germinated seeds on the third day, $D$ is the number of germinated seeds on the seventh day, $E$ is the number of total seeds investigated, $F$ is the number of germinated seeds one day, and $G$ is the days of seeds germination.

2.3. Field Trial. The field trial was conducted in the plots of the experimental field in the Liaoning Provincial Seed Group Co., Ltd, China. The soybean seeds were mixed with each of the seed-coating agents at a ratio of 1:50 $(\mathrm{w} / \mathrm{w})$ and coated by hand uniformly. After spreading and airing for about $30 \mathrm{~min}$, the seeds were sown into the field. The experiments were designed as a randomized block design with each treatment consisting of several plots separated from each other by a row $20 \mathrm{~cm}$ wide. Each plot was $4.0 \mathrm{~m}$ wide by $6.0 \mathrm{~m}$ long, contained 250 soybean seeds, and was sown either with coated seeds or with uncoated seeds to serve as control. Each treatment was replicated three times. A random sample of 100 seedlings was selected to determine the germination percentage (GP), and 100 plants were randomly selected to determine the growth indexes at flowering stage and pod-setting stage, respectively. Total yield of each plot was determined by weighing the seeds of all established plants after threshing.

\section{Results}

The artificial mixed feeds weight and mean leaf area consumed were significantly less than the control group for every chitosan treatment against agrotis ypsilon, soybean pod borer, and soybean aphid. For all chitosan treatments, the artificial mixed feeds weight and leaf area consumed declined with increasing concentration. It can be seen from Table 1 that all natural polysaccharide coating had a significant effect on antifeeding against pests; with the increasing concentration, antifeedant rates (AR) were increased obviously; especially when in the concentration of $5 \%$, antifeedant rate of agrotis ypsilon, soybean pod borer, and soybean aphid reached $82.89 \%, 87.24 \%$, and $80.21 \%$, respectively, and the best to soybean pod borer. 
TABLE 1: Effects of different treatments on the consumption of artificial mixed feeds weight and cucumber leaf area.

\begin{tabular}{lccc}
\hline & & AR $(\%)$ & \\
$\mathrm{T}$ & Agrotis ypsilon & Soybeanpod borer & Soybean aphid \\
\hline $1 \% \mathrm{NP}$ & $53.51 \pm 1.1 \mathrm{c}$ & $55.56 \pm 1.2 \mathrm{c}$ & $29.16 \pm 1.3 \mathrm{c}$ \\
$2 \% \mathrm{NP}$ & $61.40 \pm 0.9 \mathrm{c}$ & $62.14 \pm 1.0 \mathrm{c}$ & $41.55 \pm 1.1 \mathrm{c}$ \\
$3 \% \mathrm{NP}$ & $67.98 \pm 1.5 \mathrm{~b}$ & $69.55 \pm 1.5 \mathrm{~b}$ & $50.06 \pm 1.4 \mathrm{~b}$ \\
$4 \% \mathrm{NP}$ & $74.12 \pm 1.3 \mathrm{~b}$ & $72.02 \pm 1.4 \mathrm{~b}$ & $65.33 \pm 1.5$ \\
$5 \% \mathrm{NP}$ & $82.89 \pm 1.2 \mathrm{a}$ & $87.24 \pm 1.0 \mathrm{a}$ & $80.21 \pm 1.1 \mathrm{~b}$ \\
\hline
\end{tabular}

Values are expressed as mean \pm standard error. Means with different letters is significance different at $P<0.05$.

TABLE 2: Effects of different treatments on the emergence of soybean pests in the field trials.

\begin{tabular}{|c|c|c|c|c|c|c|}
\hline \multirow{3}{*}{ Treatment } & \multicolumn{2}{|c|}{ Soybean aphid emergence percentage (\%) } & \multicolumn{2}{|c|}{ No. of soybean aphid (no./plant) } & \multicolumn{2}{|c|}{ Leaf roll emergence percentage $(\%)$} \\
\hline & \multicolumn{2}{|c|}{ Weeks after planting } & \multicolumn{2}{|c|}{ Weeks after planting } & \multicolumn{2}{|c|}{ Weeks after planting } \\
\hline & 3 & 6 & 3 & 6 & 3 & 6 \\
\hline $1 \% \mathrm{NP}$ & 73.14 & 93.28 & 5875 & 37564 & 6.98. & 15.34 \\
\hline $2 \% \mathrm{NP}$ & 67.45 & 91.37 & 3276 & 35867 & 6.87 & 14.86 \\
\hline $3 \% \mathrm{NP}$ & 56.65 & 89.92 & 2094 & 26755 & 6.35 & 12.56 \\
\hline $4 \% \mathrm{NP}$ & 42.76 & 86.57 & 1889 & 19353 & 4.89 & 9.84 \\
\hline $5 \% \mathrm{NP}$ & 35.16 & 84.46 & 1574 & 14735 & 3.72 & 8.45 \\
\hline CK & 87.78 & 100 & 15650 & 58646 & 36.56 & 55.46 \\
\hline
\end{tabular}

TABLE 3: Effects of different treatments on germination abilities.

\begin{tabular}{lccc}
\hline Treatments & \multicolumn{3}{c}{ Germination abilities } \\
& GE $(\%)$ & GP $(\%)$ & GI $(\%)$ \\
\hline $1 \% \mathrm{NP}$ & $74.1 \pm 1.5 \mathrm{c}$ & $82.3 \pm 1.3 \mathrm{c}$ & $44.3 \pm 0.5 \mathrm{c}$ \\
$2 \% \mathrm{NP}$ & $75.9 \pm 1.6 \mathrm{c}$ & $82.9 \pm 1.2 \mathrm{c}$ & $45.8 \pm 0.6 \mathrm{c}$ \\
$3 \% \mathrm{NP}$ & $78.3 \pm 1.8 \mathrm{~b}$ & $88.3 \pm 1.2 \mathrm{~b}$ & $46.9 \pm 0.8 \mathrm{~b}$ \\
$4 \% \mathrm{NP}$ & $81.2 \pm 1.7 \mathrm{a}$ & $89.5 \pm 1.1 \mathrm{a}$ & $48.1 \pm 0.7 \mathrm{c}$ \\
$5 \% \mathrm{NP}$ & $81.9 \pm 1.4 \mathrm{a}$ & $92.5 \pm 1.0 \mathrm{a}$ & $49.7 \pm 0.4 \mathrm{c}$ \\
CK & $71.9 \pm 2.1$ & $79.8 \pm 1.5$ & $41.9 \pm 0.6$ \\
\hline
\end{tabular}

Values are expressed as mean \pm standard error. Means with different letters is significance different at $P<0.05$.

The field trial results indicated that chitosan coating protected soybean plant against pests efficiently (Table 2 ). Compared with CK, soybean aphid emergence and leafroll emergence percentage of soybean plants treated with chitosan were significantly reduced. With the increasing concentration of chitosan, soybean aphid emergence percentage, no. of soybean aphid, and leaf roll emergence percentage were reduced, it was observed that there were significant differences between $1 \%$ and $5 \%$ chitosan treated.

Results related to germinability (GE), germination percentage (GP), and germination index (GI) were shown in Table 3. The chitosan coating treatment resulted in a significant increase in GE, GP, and GI as compared to the blank control group (CK). The formulation with the highest concentration of chitosan (5\%) was the best treatment reaching over $90 \%$. However, it was observed that there were not significant differences between $4 \%$ and $5 \%$ chitosan treated.
The main performance indexes of soybean growth such as germination percentage, plant height, and dry weight were improved under chitosan treated. From Figure 1, there were obvious differences between coated seedlings and noncoated ones. The roots were longer and more well developed; the stems were longer and thicker than those of CK. It can be seen from Tables 4 to 5 that different concentrations had different degrees of improvement. And pest damage of seedlings and leaves greatly bated. Especially when in the concentration of $5 \%$, the yield was increased by about $20 \%$ compared with CK.

\section{Discussion}

4.1. The Mechanism of Antifeedant Effect. Our research indicated that chitosan acted as a seed-coating agent to control agrotis ypsilon, soybean pod borer and soybean aphid effectively. Chitosan stimulates plants to produce systematic antibodies, which can produce repellant effects to deter insect pests. In addition, chitosan with natural antifungal property can produce significant repellent action to crop pests $[14,15]$. Chitosan as signal molecule plays a barrier function in feeding behavior, which causes the unusual discharge of the nervous system and prevents animals from getting correct information of taste $[16,17]$.

4.2. The Mechanism of the Yield Increase Effect. Figure 2 has showed clearly that the face of seed coated with chitosan 2(a) forms a layer of chunky membrane, but this 2(b) not coated does not. Chitosan has excellent film-forming property, making it easy to form a semipermeable film on the seed surface which can maintain the seed moisture and absorb the soil moisture, and thus it can promote seed germination. 


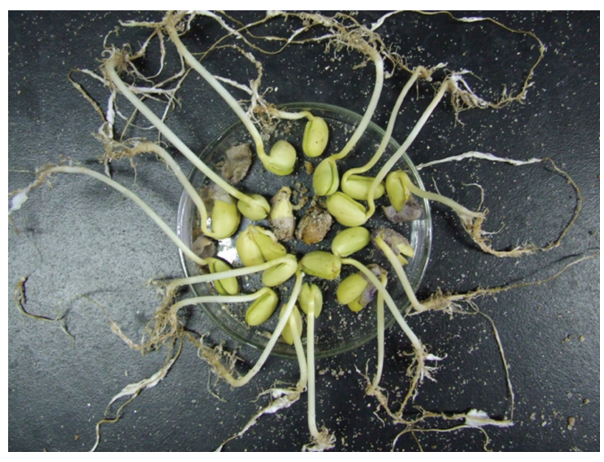

(a) Coated with NP

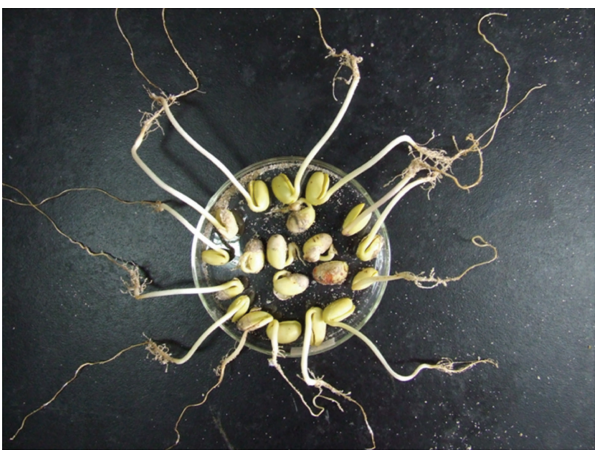

(b) CK

FIGURE 1: Contrast section photos of soybean seedling growth coated with NP and CK.

TABLE 4: Effects of different treatments on germination percentage, plant height, and dry weight in different growth period.

\begin{tabular}{|c|c|c|c|c|c|c|c|}
\hline \multirow[b]{2}{*}{ Treatment } & \multicolumn{3}{|c|}{ Seedling stage } & \multicolumn{2}{|c|}{ Full-bloom stage } & \multicolumn{2}{|c|}{ Pod bearing period } \\
\hline & $\begin{array}{c}\text { Germination } \\
\text { Percentage (\%) }\end{array}$ & $\begin{array}{c}\text { Plant height } \\
(\mathrm{cm})\end{array}$ & $\begin{array}{l}\text { Dry weight } \\
(\mathrm{g})\end{array}$ & $\begin{array}{l}\text { Plant height } \\
(\mathrm{cm})\end{array}$ & $\begin{array}{l}\text { Dry weight } \\
(\mathrm{g})\end{array}$ & $\begin{array}{l}\text { Plant height } \\
(\mathrm{cm})\end{array}$ & $\begin{array}{c}\text { Dry weight } \\
(\mathrm{g})\end{array}$ \\
\hline $1 \% \mathrm{NP}$ & 80.72 & 8.4 & 0.42 & 21.8 & 1.84 & 38.8 & 7.53 \\
\hline $2 \% \mathrm{NP}$ & 81.21 & 8.6 & 0.44 & 22.4 & 1.84 & 39.1 & 7.84 \\
\hline $3 \% \mathrm{NP}$ & 85.53 & 8.6 & 0.45 & 22.4 & 1.91 & 39.5 & 7.86 \\
\hline $4 \% \mathrm{NP}$ & 89.76 & 8.7 & 0.45 & 22.8 & 1.94 & 41.2 & 7.96 \\
\hline $5 \% \mathrm{NP}$ & 94.45 & 9.4 & 0.49 & 24.6 & 2.18 & 43.3 & 8.87 \\
\hline $\mathrm{CK}$ & 79.84 & 8.2 & 0.41 & 21.5 & 1.79 & 38.4 & 7.32 \\
\hline
\end{tabular}

TABLE 5: Effects of different treatments on yield components of soybean in the field trials.

\begin{tabular}{lccccc}
\hline Treatments & $\begin{array}{c}\text { No. of nodes } \\
\text { (no./plant) }\end{array}$ & $\begin{array}{c}\text { No. of pods } \\
\text { (no./plant) }\end{array}$ & $\begin{array}{c}\text { No. of grains } \\
\text { (no./plant) }\end{array}$ & $\begin{array}{c}100 \text {-seed } \\
\text { weight/g }\end{array}$ & $\begin{array}{c}\text { Yield } \\
\left(10^{3} \mathrm{~kg} / \mathrm{ha}\right)\end{array}$ \\
\hline $1 \% \mathrm{NP}$ & $11.8 \pm 1.4 \mathrm{c}$ & $32.5 \pm 3.2 \mathrm{c}$ & $63.2 \pm 5.5 \mathrm{c}$ & $24.42 \pm 0.3$ & $2.63 \pm 0.025 \mathrm{c}$ \\
$2 \% \mathrm{NP}$ & $12.2 \pm 1.6 \mathrm{c}$ & $33.7 \pm 2.8 \mathrm{c}$ & $65.8 \pm 5.8 \mathrm{c}$ & $25.26 \pm 0.5 \mathrm{c}$ & $2.89 \pm 0.024 \mathrm{c}$ \\
$3 \% \mathrm{NP}$ & $12.5 \pm 1.5 \mathrm{c}$ & $34.1 \pm 3.0 \mathrm{c}$ & $67.2 \pm 5.2 \mathrm{~b}$ & $25.76 \pm 0.2 \mathrm{c}$ & $2.95 \pm 0.021 \mathrm{~b}$ \\
$4 \% \mathrm{NP}$ & $12.7 \pm 1.3 \mathrm{c}$ & $34.6 \pm 2.7 \mathrm{c}$ & $68.4 \pm 5.6 \mathrm{~b}$ & $26.35 \pm 0.4 \mathrm{~b}$ & $3.05 \pm 0.023 \mathrm{a}$ \\
$5 \% \mathrm{NP}$ & $12.9 \pm 1.2 \mathrm{c}$ & $35.8 \pm 3.3 \mathrm{c}$ & $75.2 \pm 5.1 \mathrm{a}$ & $27.85 \pm 0.3 \mathrm{a}$ & $3.12 \pm 0.022 \mathrm{a}$ \\
CK & $11.2 \pm 1.7$ & $31.9 \pm 3.1$ & $60.6 \pm 5.7$ & $23.13 \pm 0.5$ & $2.58 \pm 0.024$ \\
\hline
\end{tabular}

Values are expressed as mean \pm standard error. Means within a column designated with different letters are significance different at $P<0.05$.

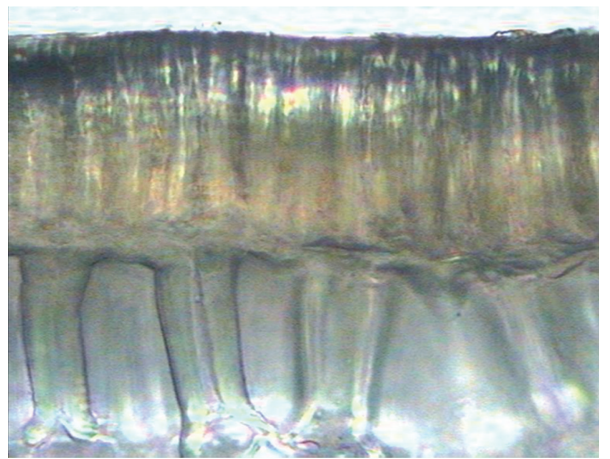

(a) Coated with NP

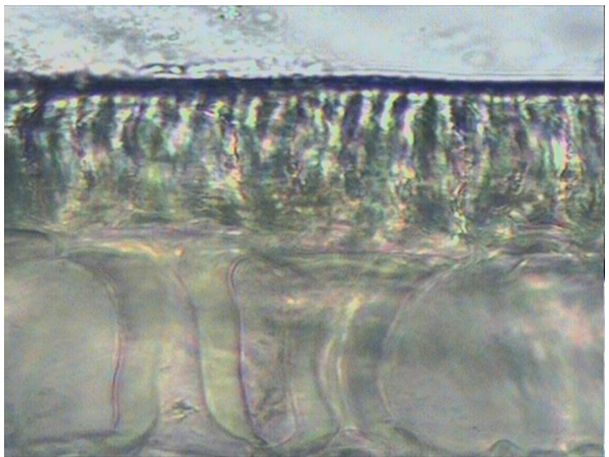

(b) $\mathrm{CK}$

FIGURE 2: Contrast section photos of coated-seeds' and uncoated-seeds' surface membrane. 
In contrast, it can cut off excessive soil moisture to prevent the seed from corrupting. Furthermore, chitosan film is also considered to have a good selective permeability, which can prevent oxygen from entering the film, restrict loss of $\mathrm{CO}_{2}$, and maintain a high concentration of $\mathrm{CO}_{2}$ in the film, so as to restrain the seed respiration and thus to make the internal nutrient consumption of seeds fall to the lowest possible level [18]. This kind of semi-permeable film is believed to be able to maintain the seed moisture and absorb the soil moisture, and thus it can promote seed germination [19]. Chitosan also can increase soluble sugar content and enhance the activity of protease conversion to protein and increasing free amino acid content, which has obvious inhibiting effect for many plant pathogenic fungi. Chitosan as a novel plant disease inhibitor can induce and improve the disease resistance of plants thus has a repellent effect to the pests in the soil [20]. Chitosan possesses the natural antifungal role, which increases the permeability of the outer membrane and inner membrane and ultimately disrupts bacterial cell membranes, with the release of cellular contents $[21,22]$.

\section{Acknowledgments}

The authors express the appreciation to the Wuhan Science and Technology Bureau of China for financial support (no. 201120922303). They also thank the State Key Laboratory of Crop Biology of Shandong Agricultural University. A special acknowledgment is given to the Wuhan University of Technology for experimental conditions and technical support.

\section{References}

[1] R. A. Omolehin, T. O. Ogunfiditimi, and O. B. Adeniji, "Factors influencing adoption of chemical pest control in cowpea production among rural farmers in Makarfi Local Government Area of Kaduna State, Nigeria," Asian Journal of Plant Sciences, vol. 3, no. 4, pp. 225-228, 2005.

[2] E. Asare-Bediako, A. A. Addo-Quaye, and A. Mohammed, "Control of diamondback moth (Plutella xylostella) on cabbage (Brassica oleracea var capitata) using intercropping with non-host crops," American Journal of Food Technology, vol. 5, no. 4, pp. 269-274, 2010.

[3] M. M. Rahman and M. M. Hossain, "Plant density effects on growth, yield and yield components of two soybean varieties under equidistant planting arrangement," Asian Journal of Plant Sciences, vol. 5, no. 10, pp. 278-286, 2011.

[4] N. E. Ahmed, H. O. Kanan, S. Inanaga, Y. Q. Ma, and Y. Sugimoto, "Impact of pesticide seed treatments on aphid control and yield of wheat in the Sudan," Crop Protection, vol. 20, no. 10, pp. 929-934, 2001.

[5] N. L. Brooker, C. D. Lagalle, A. Zlatanic, I. Javni, and Z. Petrovic, "Soy polyol formulations as novel seed treatments for the management of soil-borne diseases of soybean." Communications in Agricultural and Applied Biological Sciences, vol. 72, no. 2, pp. 35-43, 2007.

[6] X. Honglu and X. Guomei, "Suspension property of gemini surfactant in seed coating agent," Journal of Dispersion Science and Technology, vol. 29, no. 4, pp. 496-501, 2008.

[7] K. Ziani, B. Ursúa, and J. I. Maté, "Application of bioactive coatings based on chitosan for artichoke seed protection," Crop Protection, vol. 29, no. 8, pp. 853-859, 2010.
[8] M. E. Arias, J. A. González-Pérez, F. J. González-Vila, and A. S. Ball, "Soil health-a new challenge for microbiologists and chemists," International Microbiology, vol. 8, no. 1, pp. 13-21, 2005.

[9] H. F. Huiting and A. Ester, "Effects of seed coatings with thiamethoxam on germination and flea beetle control in flax," Communications in Agricultural and Applied Biological Sciences, vol. 72, no. 3, pp. 595-601, 2007.

[10] S. Bautista-Banos, M. Hernandez-Lopez, and E. BosquezMolina, "Growth inhibition of select fungi by chitosan and plant extracts," Mexican Journal of Phytopathology, vol. 22, pp. 178-186, 2004.

[11] M. Rinaudo, "Chitin and chitosan: properties and applications," Progress in Polymer Science, vol. 31, no. 7, pp. 603-632, 2006.

[12] H. Tang, P. Zhang, T. L. Kieft et al., "Antibacterial action of a novel functionalized chitosan-arginine against Gram-negative bacteria," Acta Biomaterialia, vol. 6, no. 7, pp. 2562-2571, 2010.

[13] X. H. Wu, W. H. Zhang, and P. F. Liu, "Research and development trend of the seed coating agent in China," Plant Protection and Promotion of Technology, vol. 10, pp. 36-38, 2003.

[14] N. Shibuya and E. Minami, "Oligosaccharide signalling for defence responses in plant," Physiological and Molecular Plant Pathology, vol. 59, no. 5, pp. 223-233, 2001.

[15] P. P. Ma and L. Q. He, "Progress of chitosan in suppression of plant diseases," Natural Product Research and Development, vol. 13, no. 6, pp. 82-86, 2001.

[16] T. Tokunaga, N. Takada, and M. Ueda, "Mechanism of antifeedant activity of plumbagin, a compound concerning the chemical defense in carnivorous plant," Tetrahedron Letters, vol. 45, no. 38, pp. 7115-7119, 2004.

[17] D. R. Perera, G. Armstrong, and N. Senanayake, "Effect of antifeedants on the diamondback moth (Plutella xylostella) and its parasitoid Cotesia plutellae," Pest Management Science, vol. 56, no. 5, pp. 486-490, 2002.

[18] R. T. Furbank, R. White, J. A. Palta, and N. C. Turner, "Internal recycling of respiratory $\mathrm{CO}_{2}$ in pods of chickpea (Cicer arietinum L.): the role of pod wall, seed coat, and embryo," Journal of Experimental Botany, vol. 55, no. 403, pp. 16871696, 2004.

[19] W. V. Sigler and R. F. Turco, "The impact of chlorothalonil application on soil bacterial and fungal populations as assessed by denaturing gradient gel electrophoresis," Applied Soil Ecology, vol. 21, no. 2, pp. 107-118, 2002.

[20] H. P. Chen and L. L. Xu, "Progress of study on chitosan in regulating plants' growth and eliciting plants' defense responses," Acta Botanica Yunnanica, vol. 27, no. 6, pp. 613-619, 2005.

[21] H. Liu, Y. Du, X. Wang, and L. Sun, "Chitosan kills bacteria through cell membrane damage," International Journal of Food Microbiology, vol. 95, no. 2, pp. 147-155, 2004.

[22] K. K. Nielsen, P. Jorgensen, and J. D. Mikkelsen, "Antifungal activity of sugar beet chitinase against Cercospora beticola: an autoradiographic study on cell wall degradation," Plant Pathology, vol. 43, no. 6, pp. 979-986, 1994. 


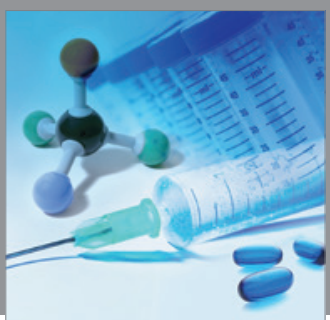

International Journal of

Medicinal Chemistry

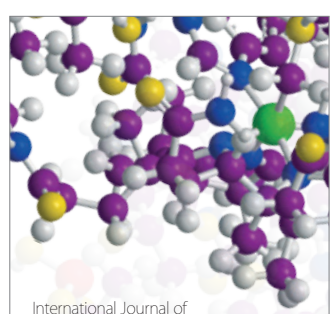

Carbohydrate Chemistry

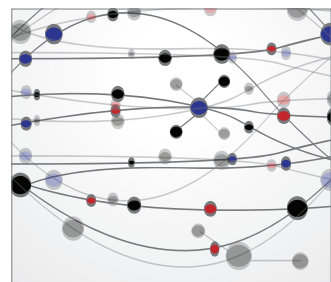

The Scientific World Journal
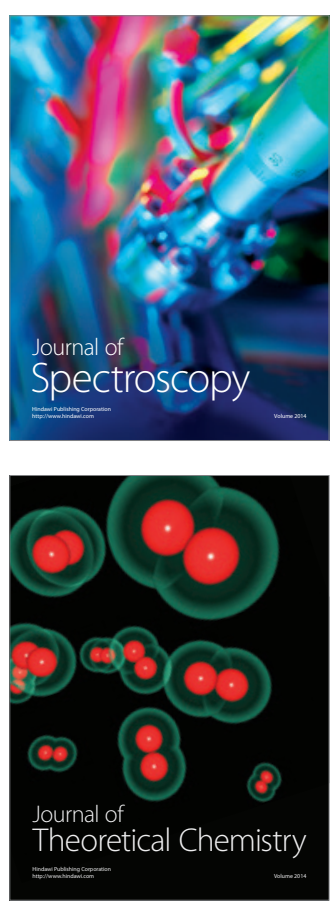
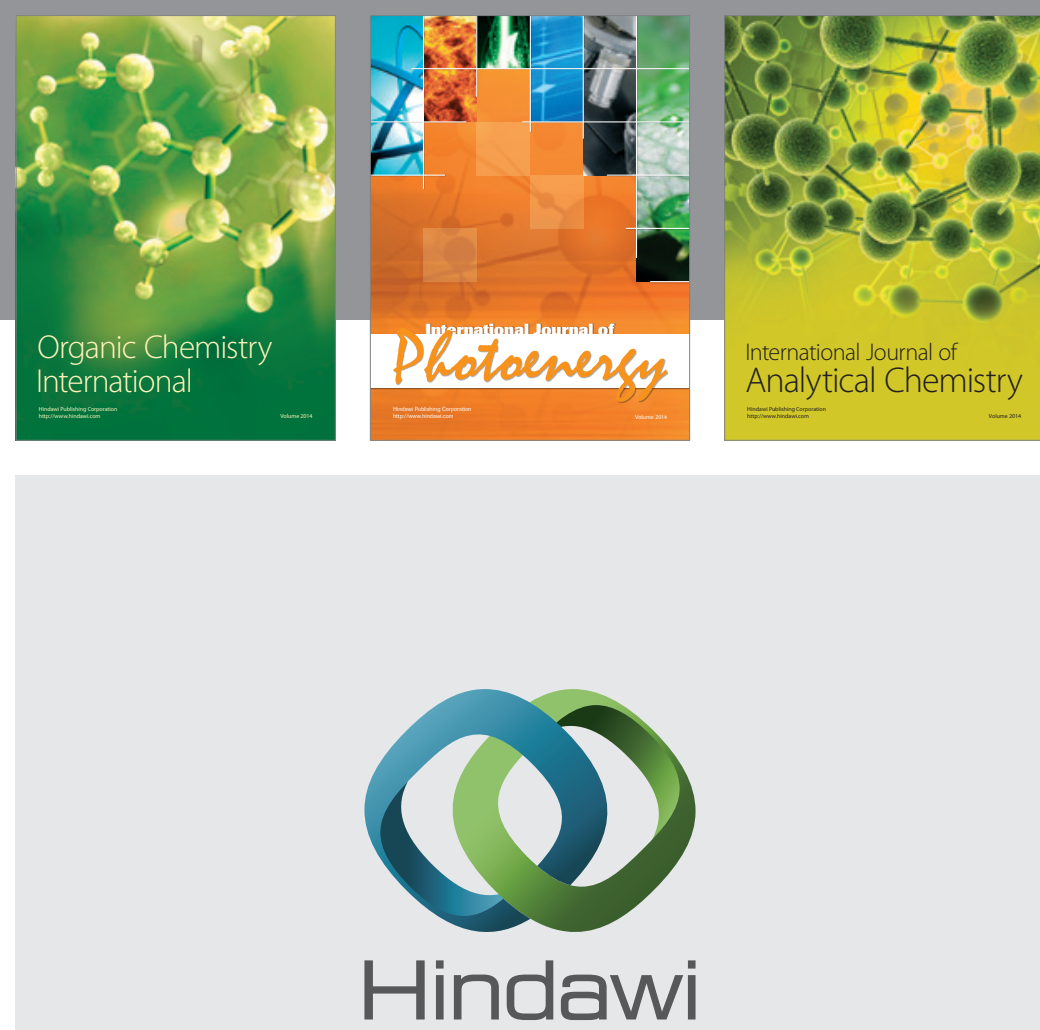

Submit your manuscripts at

http://www.hindawi.com
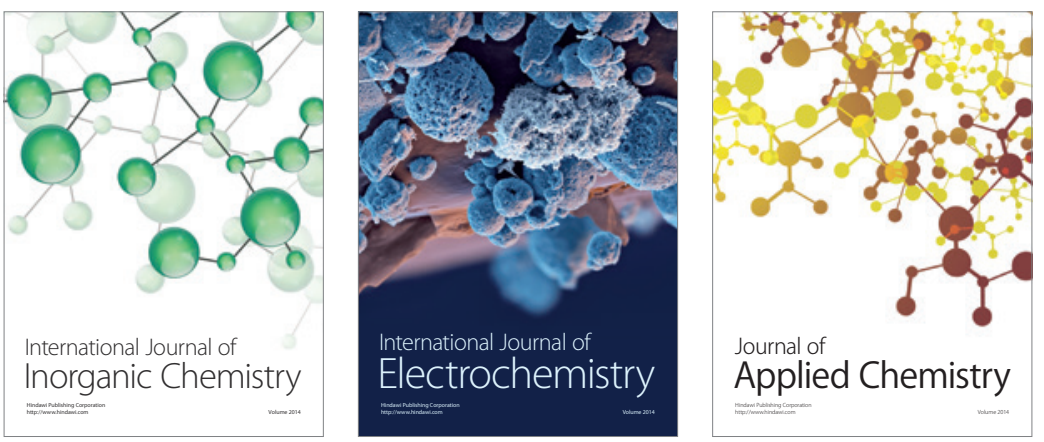

Journal of

Applied Chemistry
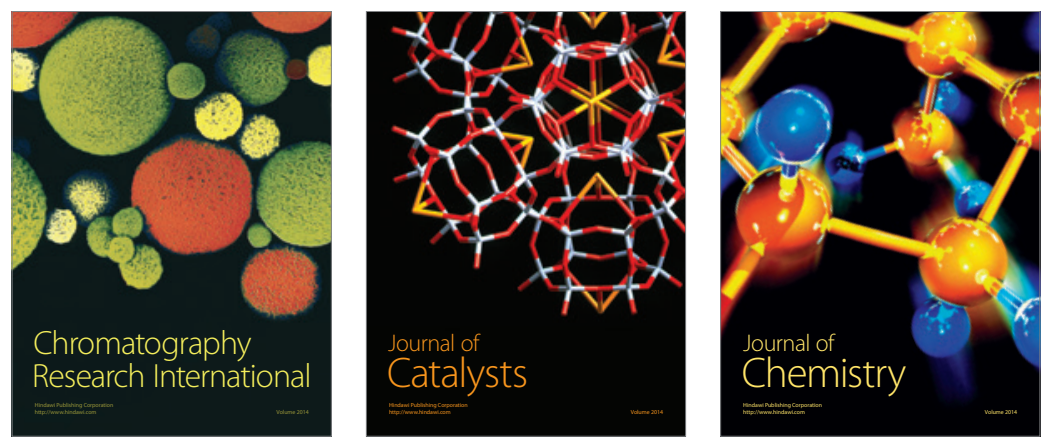
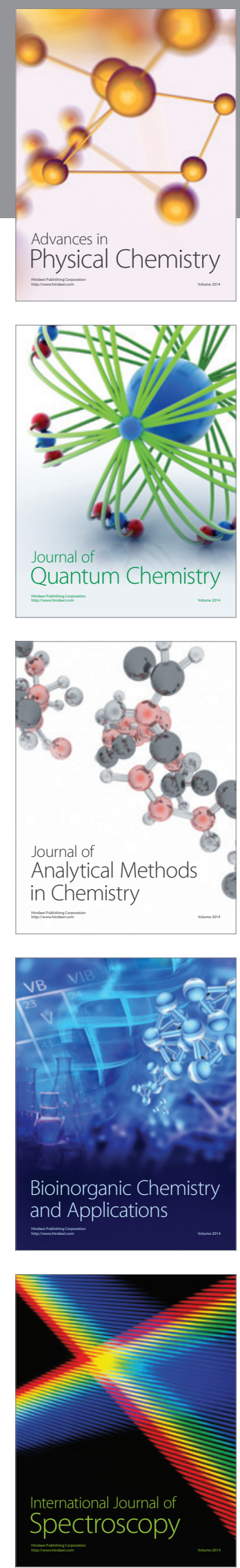